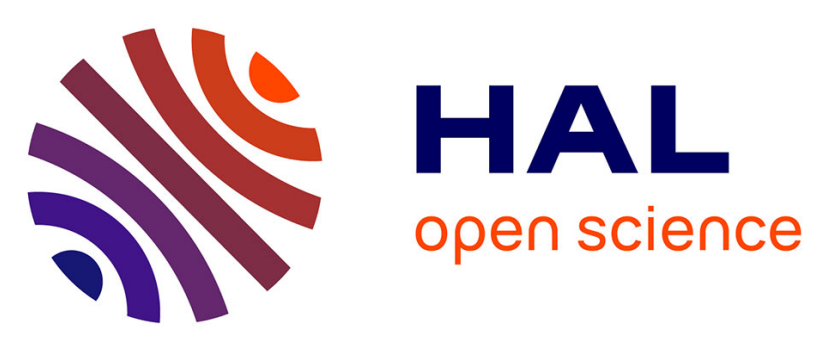

\title{
Atomic scale characterization of a pure Al - galvanized steel spot magnetic pulse joint interface
}

Marie-Noëlle Avettand-Fènoël, Roland Taillard, Maya Marinova

\section{To cite this version:}

Marie-Noëlle Avettand-Fènoël, Roland Taillard, Maya Marinova. Atomic scale characterization of a pure $\mathrm{Al}$ - galvanized steel spot magnetic pulse joint interface. Materials Characterization, 2019, Materials Characterization, 153, pp.251-260. 10.1016/j.matchar.2019.05.016 . hal-02165629

\section{HAL Id: hal-02165629 \\ https://hal.univ-lille.fr/hal-02165629}

Submitted on 22 Oct 2021

HAL is a multi-disciplinary open access archive for the deposit and dissemination of scientific research documents, whether they are published or not. The documents may come from teaching and research institutions in France or abroad, or from public or private research centers.
L'archive ouverte pluridisciplinaire HAL, est destinée au dépôt et à la diffusion de documents scientifiques de niveau recherche, publiés ou non, émanant des établissements d'enseignement et de recherche français ou étrangers, des laboratoires publics ou privés.

\section{(c) (1) $\$$}

Distributed under a Creative Commons Attribution - NonCommerciall 4.0 International 


\title{
Atomic scale characterization of a pure Al - galvanized steel spot magnetic pulse joint interface.
}

\author{
M.-N. Avettand-Fènoël ${ }^{1 *}$, M. Marinova ${ }^{2}$, R. Taillard ${ }^{1}$ \\ ${ }^{1}$ Univ. Lille, CNRS, INRA, ENSCL, UMR 8207 - UMET - Unité Matériaux et \\ Transformations, 59000 Lille, France \\ ${ }^{2}$ Centre Commun de Microscopie, Université de Lille, 59655 Villeneuve d'Ascq, France \\ * Corresponding author \\ marie-noelle.avettand-fenoel@univ-lille.fr
}

\begin{abstract}
The bonding interface of pure $\mathrm{Al}$ - galvanized steel spot magnetic pulse welds was characterized at the atomic scale. The Al-Zn interface microstructure is worthy of attention as it contains a few micrometers thick biphased layer. This singular layer consists of an aggregate of grains with a 200 to $400 \mathrm{~nm}$ size containing islands of either Al or Zn solid solutions oversaturated in $\mathrm{Zn}$ or $\mathrm{Al}$, respectively. Inside a grain, some mottled contrasts with a size in-between 5 and $10 \mathrm{~nm}$ correspond to fluctuant solute contents. Besides, some native oxides have been dissolved at the interface suggesting the incorporation of oxygen atoms in the biphased layer. Large and elongated ( $\mathrm{Al}, \mathrm{Fe}, \mathrm{Si})$ particles primitively contained in the base $\mathrm{Al}$ were also dissolved which gives rise to some round shaped $\mathrm{Si}$ particles in the biphased layer. All these microstructural features and changes are consistent with a ballistic origin. Due to both the absence of solidification defects and the rather planar morphology of the bonding interface, the process is expected to occur at the solid state.
\end{abstract}

Keywords: Aluminum - galvanized steel spot magnetic pulse welding; Interface; Microstructure; HAADF; HR(S)TEM; STEM-EDX

\section{Introduction}

Dissimilar assemblies with partial replacement of steel by light materials are of crucial importance in automotive industry for both energy cost-savings and reduction of exhaust fumes required for environment protection. Galvanized steel is used in automotive industry for corrosion resistance. However joining aluminum with galvanized steel remains a challenge since these materials are characterized by different melting points, thermal conductivities, coefficients of thermal expansion, mechanical properties and flow laws [1-3]. In addition, the high chemical affinity between $\mathrm{Al}$ and $\mathrm{Fe} \mathrm{[4]} \mathrm{may} \mathrm{lead} \mathrm{to} \mathrm{the} \mathrm{precipitation} \mathrm{of}$ brittle intermetallic compounds (IMCs) [1-2] at the joint interface. Diffusion is all the more favored that joining proceeds at the liquid state in the case of welding or brazing. The presence of $\mathrm{Zn}$ at the steel surface, with a melting point far lower than those of $\mathrm{Al}$ and steel, may further promote $\mathrm{Al}$ and Fe diffusion [5]. The formation of thick continuous IMCs at a joint interface is well known to be harmful for the ductility and then the soundness of the joint [56]. The use of solid state thermomechanical processes is thus particularly recommended since they should limit the formation of IMCs. Nevertheless, the latter processes are characterized by high strains and strain rates which generate very high densities of vacancies favoring again atomic diffusion [6-97-10]. 
High velocity impact welding techniques, among which Magnetic Pulse Spot Welding (MPSW), are smart processes able to solve the problem of dissimilar joining. Derived from high speed magnetic pulse forming, MPSW is an environmental friendly and energy saving solid state process which only lasts a few microseconds [1011]. This time is far shorter than the duration of usual solid state thermomechanical processes, like friction or friction stir welding processes, which are characterized by welding cycles of a few seconds. MPW is a shock welding process where the current pulse passing through an electromagnetic coil produces high magnetic forces. Such forces propel a flyer sheet towards a static sheet, which leads to the bonding of both sheets [1011]. MPSW brings about a low heat input to materials, which should limit the formation of IMCs and reduce the heat affected zone extent [10-121113].

With regards to the Al-steel system, various MPW joints were obtained in a tubular [13-2314-24] or planar [12,24-2913,25-30] configuration. No work reports MPSW between galvanized steel and aluminum except a paper of the present authors who have considered magnetic pulse spot joining of hot dip galvanized steel with AA1050 pure aluminum [3031]. The architecture of the interface was investigated at a mesoscopic scale. Going from pure Al to steel, the interface is constituted of four successive layers: (i) a 10 at. \% $\mathrm{Zn}$ oversaturated $\mathrm{Al}$ solid solution, (ii) an ( $\mathrm{Al}+\mathrm{Zn}$ ) aggregate of $\mathrm{Al}$ and $\mathrm{Zn}$ grains, (iii) a $\mathrm{Zn}$ layer and (iv) the inhibition layer. The total thickness of the $(\mathrm{Al}+\mathrm{Zn})$ mixture and of the remaining $\mathrm{Zn}$ layer corresponds to the initial thickness of the Zn coating on steel.

The present paper characterizes the $(\mathrm{Al}+\mathrm{Zn})$ mixed layer at the atomic scale. This in-depth investigation will provide clues about the mechanism of formation of the bi-phased layer which can be deleterious for the joint mechanical properties. This joint indeed fractured in this bi-phased layer during shear-tensile tests [3031], very likely because of the low plasticity of $\mathrm{Zn}$.

\section{Experimental procedure}

The base materials are $40 \mathrm{~mm}$ wide coupons of AA1050 aluminum $(90 \mathrm{~mm}$ long and $0.5 \mathrm{~mm}$ thick, hardness of $\left.40 \mathrm{HV}_{0.05}\right)$ and of hot-dip galvanized cold rolled DP450 steel (110 $\mathrm{mm}$ long and $1.17 \mathrm{~mm}$ thick, hardness of $160 \mathrm{HV}_{0.05}$ ). The galvanized coating on DP450 steel is $11 \mu \mathrm{m}$ thick. The chemical compositions of the base materials supplied by the provider are indicated in Table 1. Aluminum which is the better electrical conductor constitutes the flyer sheet whereas steel with its higher yield strength is the target workpiece. A $8 \mathrm{~mm}$ wide and 12 $\mathrm{mm}$ long hump was deep drawn on the Al flyer sheet. The sheets were cleaned with acetone and stacked over a lap-length of $50 \mathrm{~mm}$. They were finally joined by magnetic pulse spot welding with a discharge energy of $10 \mathrm{~kJ}$. The setting is displayed in figure 1 . The generator is characterized by a capacitance of $408 \mu \mathrm{F}$, an inductance of $100 \mathrm{nH}$ and a resistance of 14 $\mathrm{m} \Omega$. The $\mathrm{Cu}$ inductor presents a $20 \mathrm{~mm}$ long and $2.7 \mathrm{~mm}$ thick active zone, a $44 \mathrm{nH}$ inductance and a $0.1 \mathrm{~m} \Omega$ resistance. An insulating sheet with a thickness of $0.1 \mathrm{~mm}$ is inserted at the $\mathrm{Al}$ - inductor interface. Then the stand-off distance corresponds to the hump depth that is $1.5 \mathrm{~mm}$. Further details are given in the previous paper [3031].

Table 1: Chemical composition of the base materials (wt.\%)

\begin{tabular}{|c|c|c|c|c|c|c|c|c|c|c|c|c|}
\hline & $\mathrm{Al}$ & $\mathrm{Fe}$ & $\mathrm{Si}$ & $\mathrm{Cu}$ & $\mathrm{Mn}$ & $\mathrm{Mg}$ & $\mathrm{Zn}$ & $\mathrm{Ti}$ & $\mathrm{C}$ & $\mathrm{P}$ & $\mathrm{Cr}$ & Mo \\
\hline AA 1050 & balance & 0.40 & 0.25 & 0.05 & 0.05 & 0.05 & 0.07 & 0.05 & - & - & - & - \\
\hline $\begin{array}{c}\text { DP450 } \\
\text { steel }\end{array}$ & $\begin{array}{c}0.015- \\
0.08\end{array}$ & balance & $\begin{array}{c}0.400 \\
\max \end{array}$ & - & $\begin{array}{l}1.600 \\
\max \end{array}$ & - & - & $\begin{array}{c}\mathrm{Ti}+ \\
\mathrm{Nb} \\
0.050 \\
\max \end{array}$ & $\begin{array}{c}0.100 \\
\max \end{array}$ & $\begin{array}{c}0.040 \\
\max \end{array}$ & $\begin{array}{c}0.800 \\
\max \end{array}$ & $\begin{array}{c}0.300 \\
\max \end{array}$ \\
\hline
\end{tabular}




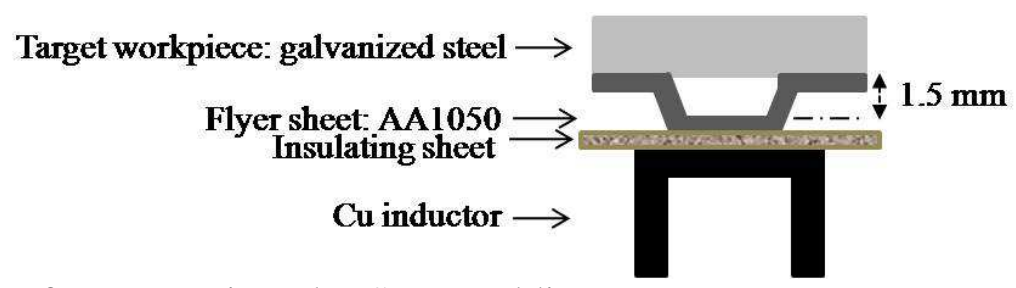

Figure 1: Setting for Magnetic Pulse Spot Welding.

The transverse cross section of the joints was prepared using standard procedure and finally polished with $1 \mu \mathrm{m}$ diamond paste.

In order to complete its previous mesoscopic analyses [3931], the joint interface was studied by high resolution scanning transmission electron microscopy (STEM) coupled to Xray energy dispersive spectroscopy (EDX). The analysis was achieved by means of a TITAN Themis $300 \mathrm{~S} / \mathrm{TEM}$ with a probe aberration corrector and monochromator, allowing spatial resolution of $70 \mathrm{pm}$ and energy resolution of $150 \mathrm{meV}$. The microscope is equipped with a super-X windowless 4 quadrant SDD (silicon drift detector) detection system for the STEMEDX mapping and with several annual dark field detectors. The experiment has been performed with a $0.5 \mathrm{~nm}$ probe size, a convergence angle of $21 \mathrm{mrad}$ and a probe current of approximately $100 \mathrm{pA}$. For the high angle annular dark field (HAADF) images collection angles have been between 50 and $200 \mathrm{mrad}$. Orientation maps were acquired on a Tecnai G2 20 Twin microscope operating at $200 \mathrm{kV}$ and equipped with a $\mathrm{LaB}_{6}$ filament and the ASTAR $^{\mathrm{TM}}$ tool. The TEM was set in micro-beam mode (5 $\mathrm{nm}$ probe size) and smallest condenser aperture $(50 \mu \mathrm{m})$ with precessed illumination (precession angle of $1 \mathrm{deg}$ ), a scanning step size of $10 \mathrm{~nm}$ and an exposure time of $20 \mathrm{~ms}$. The thin foils (figure 2) have been prepared by the Focused Ionic dual Beam (FIB) technique. During cutting, the thin foil edge facing the ion beam was protected by a $3.5 \mu \mathrm{m}$ thick deposit of platinum. A $300 \mathrm{pA}$ beam intensity was applied for the final thinning.

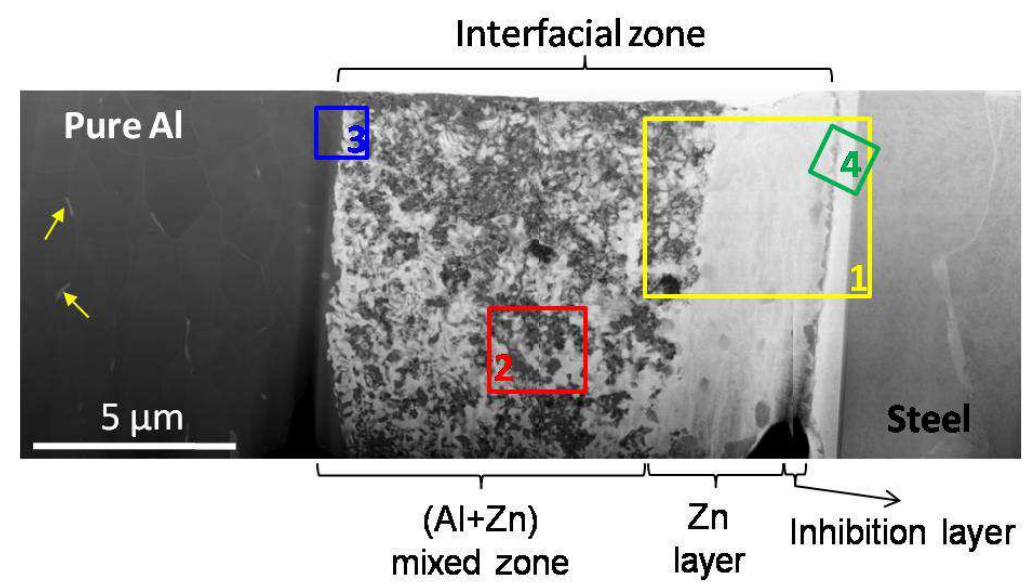

Figure 2: General aspect of a thin foil cut along the joint transverse section (HAADF image).

\section{Results}

As aforesaid, from steel to pure aluminum, the interfacial zone is successively composed of (i) a $150 \mathrm{~nm}$ thick inhibition layer, (ii) a $3 \mu \mathrm{m}$ thick Zn layer, (iii) a $8 \mu \mathrm{m}$ thick $(\mathrm{Al}+\mathrm{Zn}$ ) mixed layer (figure 2) and (iv) an $\mathrm{Al}$ solid solution containing 10 at.\% of $\mathrm{Zn}$ [3031].

Given the too small thickness of the inhibition layer compared to the size of the X-rays irradiated zone, the determination of its chemical composition was not possible by EDX. It is 
however well known that the inhibition layer is generally constituted of $\mathrm{Fe}_{2} \mathrm{Al}_{5} \mathrm{Zn}_{\mathrm{x}}$ and $\mathrm{FeAl}_{3} \mathrm{Zn}_{\mathrm{x}}$ intermetallic compounds [3132].

Figures $4 \mathrm{a}, 4 \mathrm{~b}$ and $4 \mathrm{c}$ depict the ragged morphology of the microstructure in the $\mathrm{Al}+$ $\mathrm{Zn}$ mixed zone. This layer consists in a random distribution of aggregates of either Al-rich or $\mathrm{Zn}$ rich grains. The 50 to $450 \mathrm{~nm}$ size of the latter grains is markedly smaller than the $1 \mu \mathrm{m}$ mean grain size of both the $\mathrm{Al}$ and $\mathrm{Zn}$ base material. It is thus concluded that recrystallization has occurred during either welding or the subsequent thin foil preparation by ion polishing.

Besides, it is worth noting the presence of oxygen as well as of silicon bearing spheroidal areas in the $(\mathrm{Al}+\mathrm{Zn})$ mixed zone (figure 3$)$. In addition, silicon is not linked to iron in this intermediate layer (figure 3). The mean chemical composition of these $\mathrm{O}$ and $\mathrm{Si}$ rich particles (marked by a white arrow in figure 4) is $47.6 \% \mathrm{Al}-28.3 \% \mathrm{Si}-24.1 \% \mathrm{Zn}$ (at.\%) according to the EDX analyses. Due to the larger volume of the analyzed zone compared to the particles' size, their $\mathrm{Al}$ and $\mathrm{Zn}$ contents are however overestimated. The presence of $\mathrm{Al}$ and $\mathrm{Zn}$ may also be an artifact due to the particle embedment within the mixed $(\mathrm{Al}+\mathrm{Zn})$ layer.

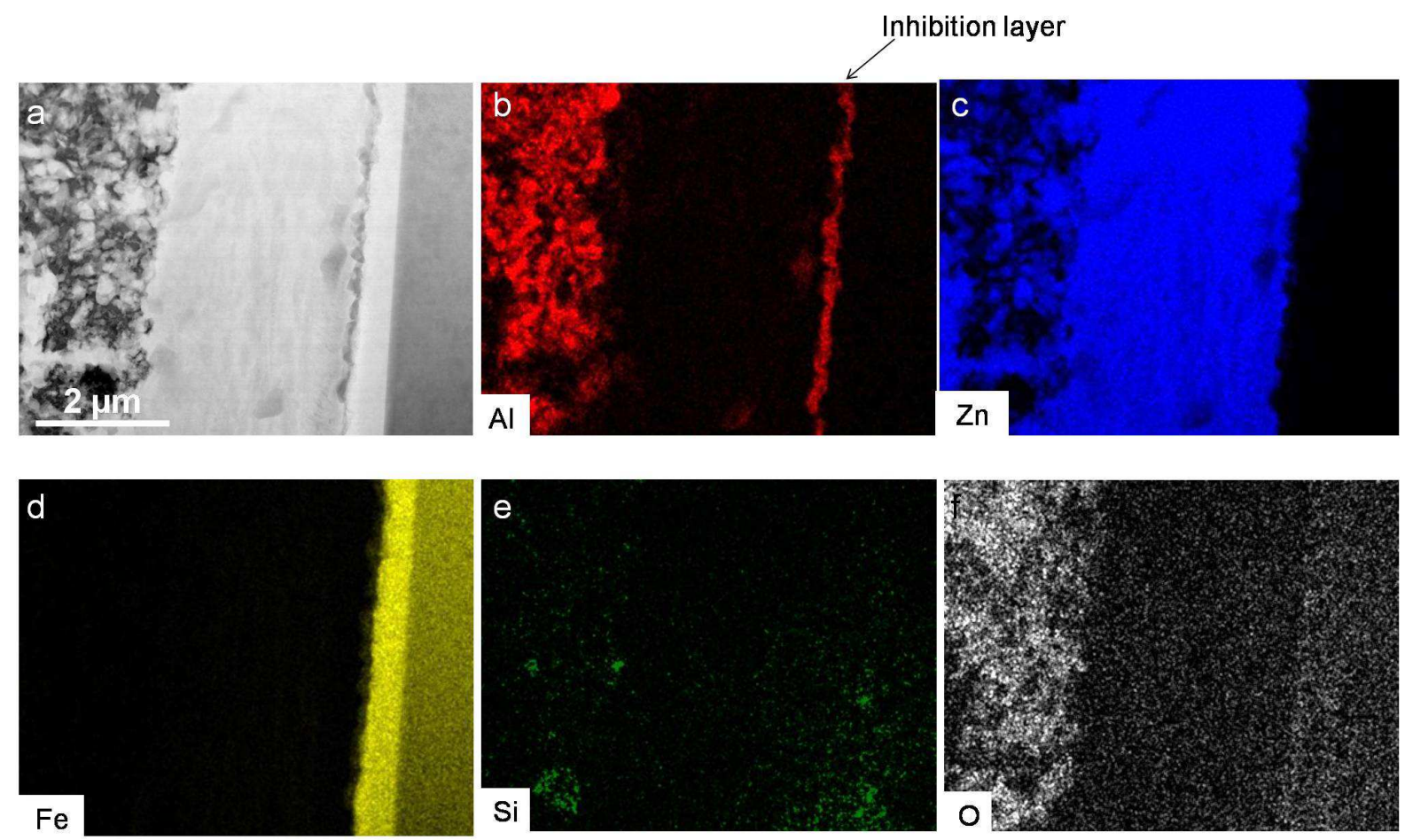

Figure 3: Details of the rectangular zone 1 in figure 2. On-line HAADF image (a) and STEMEDX maps of $\mathrm{Al} \mathrm{K}(\mathrm{b}), \mathrm{Zn} \mathrm{K}_{\alpha}(\mathrm{c}), \mathrm{Fe} \mathrm{K}_{\alpha}$ (d), Si $\mathrm{K}_{\alpha}$ (e) and $\mathrm{O} \mathrm{K}_{\alpha}$ (f). The brightest zone in the $\mathrm{Fe} \mathrm{K}_{\alpha} \mathrm{X}$-ray map is due to local thin foil thickening. 

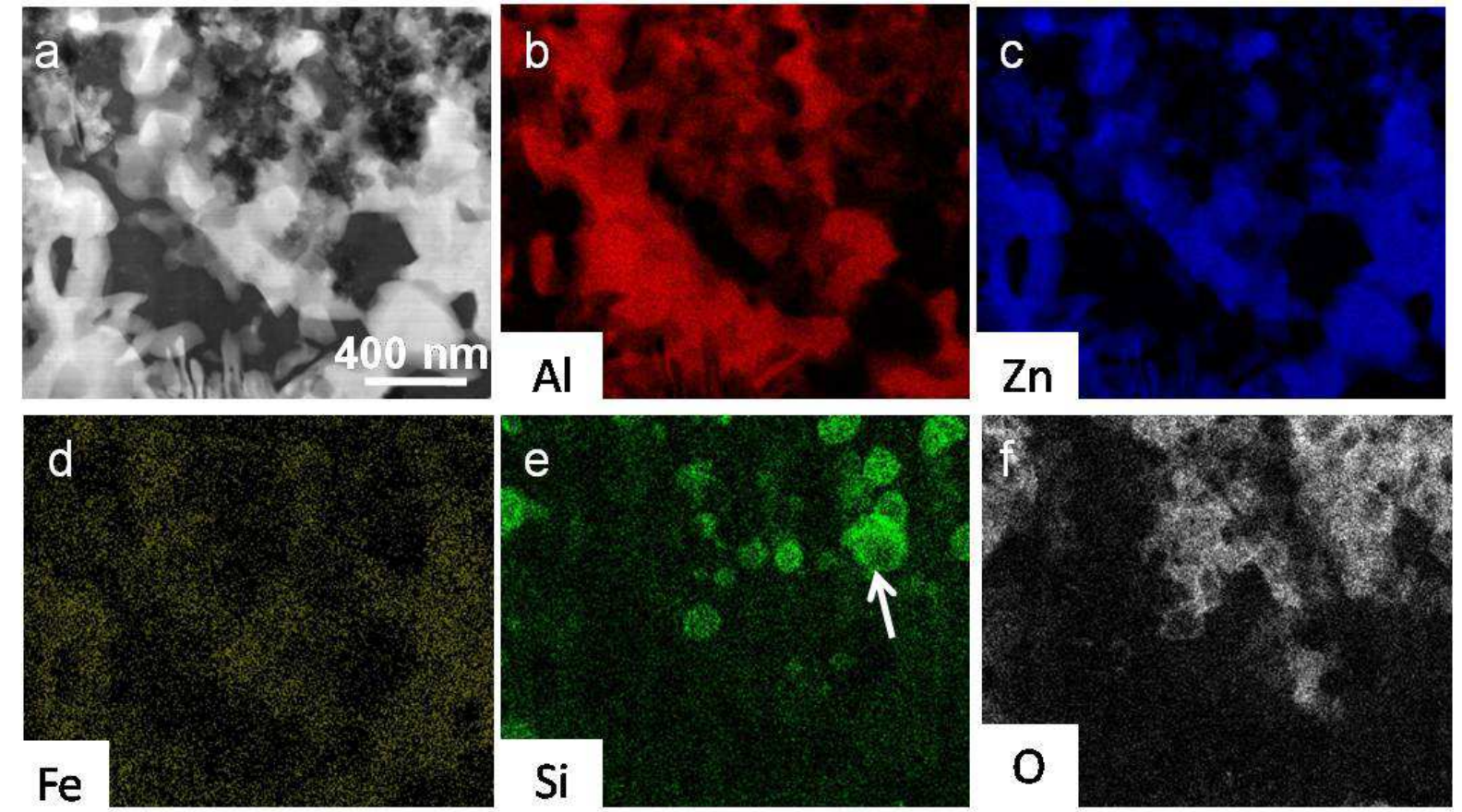

Figure 4: Details of zone 2 in figure 2. On-line HAADF image (a) and STEM-EDX maps of Al $K_{\alpha}$ (b), Zn $K_{\alpha}$ (c), Fe $K_{\alpha}$ (d), Si $K_{\alpha}$ (e) and $\mathrm{O} K_{\alpha}$ (f). It is worth noting that the $\mathrm{Fe}$ distribution is rather homogeneous-low at thea mean 0.25 at.\% content. whatever the $\mathrm{Al}$ or $\mathrm{Zn}$ based grainsBesides $\mathrm{Fe}$ is more concentrated in $\mathrm{Zn}$ areas.

With regard again to the intermediate $(\mathrm{Al}+\mathrm{Zn})$ mixed zone, the micrographs at a microscopic (figures 3 and 4) and at an atomic scale (figures 5 and 6) display some mottled contrasts in both $\mathrm{Al}$ and $\mathrm{Zn}$ rich zones. These changes of contrast are randomly dispersed. The contrast in HAADF images is proportional to the sample thickness and to the atomic number $\mathrm{Z}$ to the power of 1.7 [3233] of the elements present within the material. Thus areas with higher $\mathrm{Zn}(\mathrm{Z}=30)$ concentration will appear brighter than $\mathrm{Al}(\mathrm{Z}=13)$ rich zones. In order to understand further the variations of contrast in the HAADF images we have looked through the change in chemical composition by EDX coupled to local changes in crystal lattice. The variation of the HAADF contrast does not correspond to change in crystal orientation as confirmed by FFT (Fast Fourier Transform) patterns in the respective areas. No subgrains boundaries are detected either. Some examples are depicted in figures 5 and 6 . Figure 5 shows the atomic column arrangement in an $\mathrm{Al}$ grain oriented along a [-112] zone axis. According to EDX analyses, the grain is locally enriched with $\mathrm{Zn}$. Its atomic content is in between 3.5 at\% and 7.8 at $\%$. It then suggests the existence of $(\mathrm{Al})_{\mathrm{Zn}}$ solid solutions. Figures 6 and 7 display the atoms arrangement along the (0001) basal plane of $\mathrm{Zn}$. The EDX analysis reveals the existence of a $(\mathrm{Zn})_{\mathrm{Al}}$ solid solution with $\mathrm{Al}$ content in-between 9.4 at\% and 22.4 at.\%.

The analysis of the atomic resolution HAADF images (figures 5 and 6) gives the distances and angles between the atom planes which identifies their Miller indexes and their zone axis. The precision on interplanar distances and lattice parameters amounts to $0.04 \mathrm{~nm}$. Then the $\mathrm{Zn}$ and $\mathrm{Al}$ apparent crystal lattice parameters are deduced from the data. The experimental atomic volumes have finally been calculated by taking into account the crystallographic data and the difference of compactness of the two crystal lattices. Although $\mathrm{Al}$ and $\mathrm{Zn}$ present distinct crystal lattice structures, respectively face cubic centered and hexagonal, the Vegard's law has been applied to the Al-Zn system. It is worth noting that this 
reasoning has already been used in literature for elements with different crystal structures [3334]. From the experimental atomic volumes and the Vegard's law, it has been possible to estimate the amount of $\mathrm{Zn}$ (or $\mathrm{Al}$ ) in solid solution in $\mathrm{Al}$ (or in $\mathrm{Zn}$ ), respectively (red and green squares in figure 8). The latter contents compared with those determined locally in the same areas by EDX are summarized in figure 8 . The analysis of the inter-planar distances confirms the existence of $\mathrm{Al}$ and $\mathrm{Zn}$ solid solutions but the solutes contents determined by application of the Vegard's law are generally slightly higher, in particular for the Al solid solutions, than those measured by EDX (figure 8). Figure 8 displays a negative deviation to Vegard's law. It can be explained by the competition between electronic interactions between both elements and the volume change entailed by the size difference of the substitutional element [3435]. The presence of a random distribution of brighter atoms (corresponding to $\mathrm{Zn}$ atoms) in the zone bordered by a blue circle in figure 9 is a clear indication of the presence of random solid solutions.
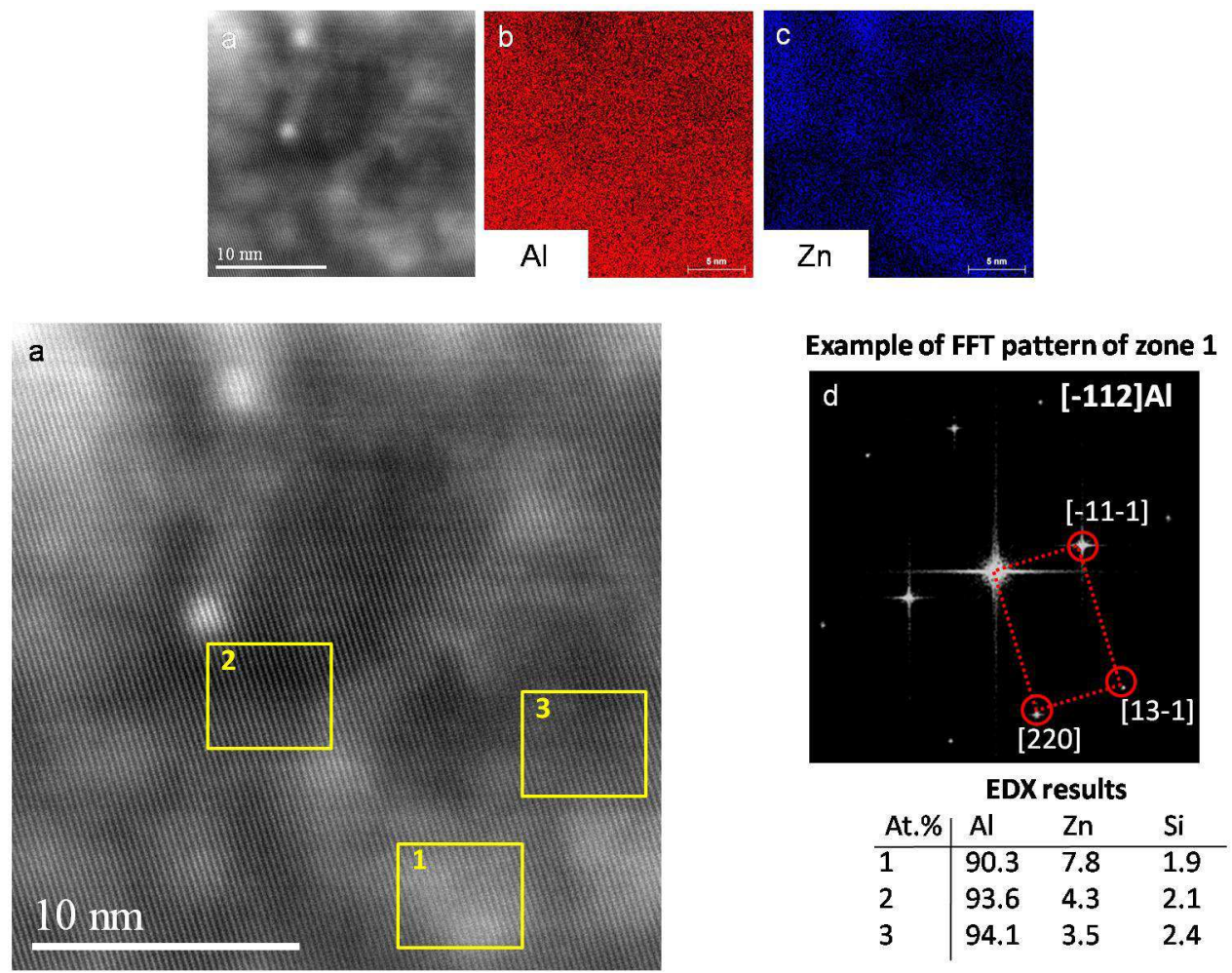

Figure 5: Al rich zone in the intermediate area: on-line HAADF image (a) with associated $\mathrm{Al}$ $\mathrm{K}_{\alpha}$ (b), Zn $\mathrm{K}_{\alpha}$ (c) X-ray maps. HAADF image (a), FFT pattern (d) and EDX results of the areas marked in the HAADF image (a). Micrograph (a) is presented at two magnifications. 

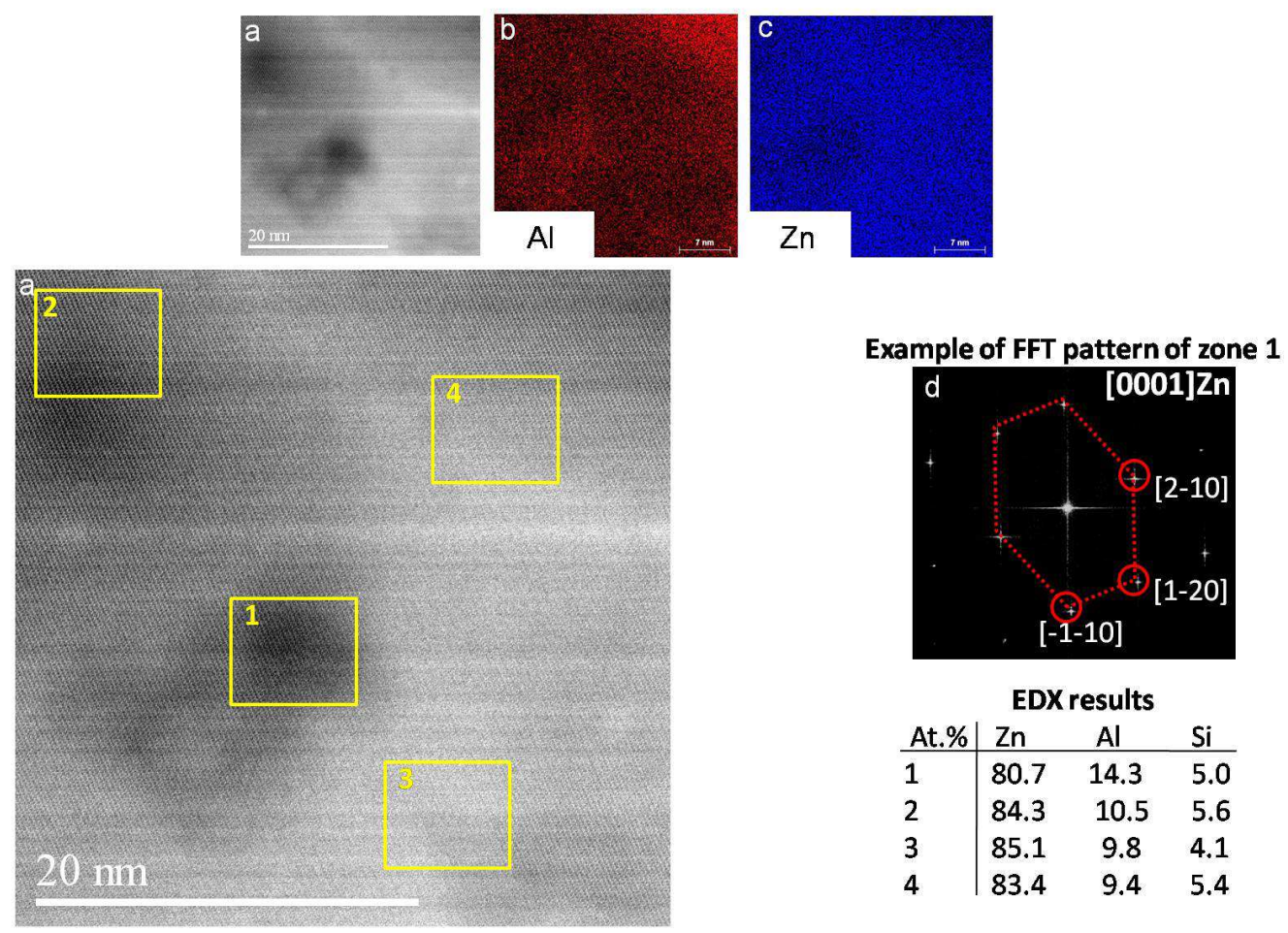

Figure 6: Zn rich zone in the intermediate area: i) HAADF image (a) and FFT pattern (d) of the zones marked in the HAAADF image, ii) on-line HAADF image (a) with associated Al $\mathrm{K}_{\alpha}(\mathrm{b}), \mathrm{Zn} \mathrm{K}_{\alpha}$ (c) X-ray maps. Micrograph (a) is presented at two magnifications.
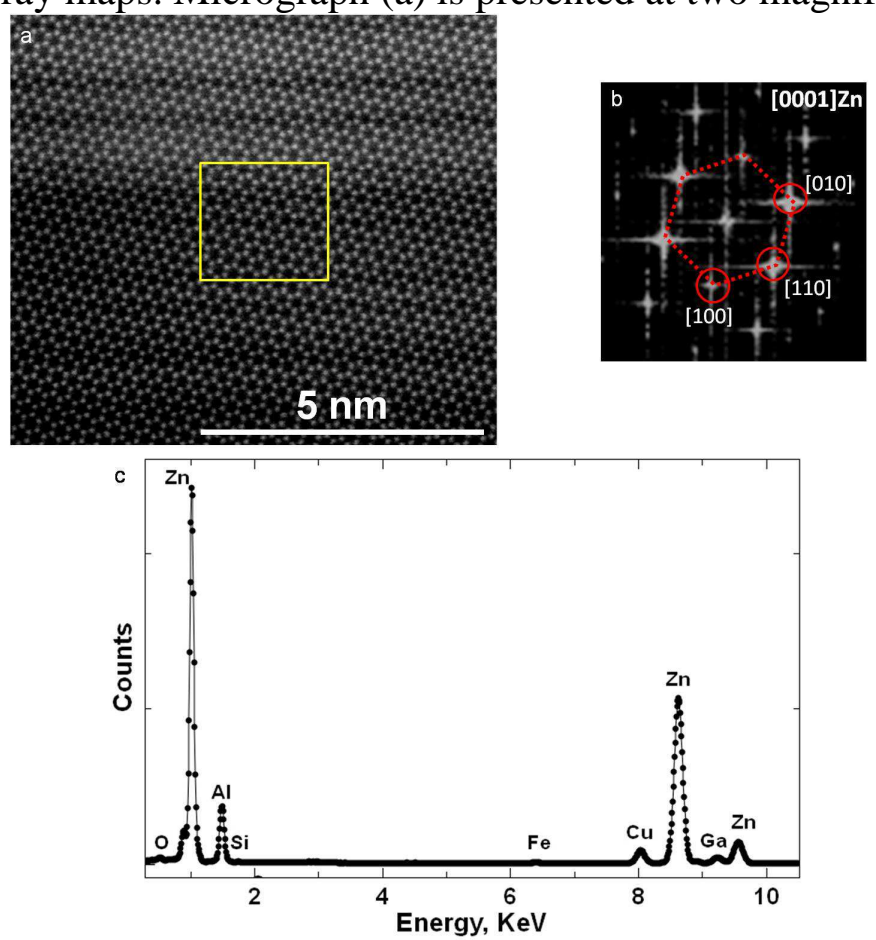

Figure 7: Atomic scale analysis of a $\mathrm{Zn}$ rich zone inside the intermediate area: HAADF image (a) and FFT pattern (b) of the zone marked in the HAADF image. The EDX spectrum (c) of this encircled zone indicates the following composition: $76.8 \% \mathrm{Zn}-22.4 \% \mathrm{Al}-0.8 \% \mathrm{Si}$ (at\%). 


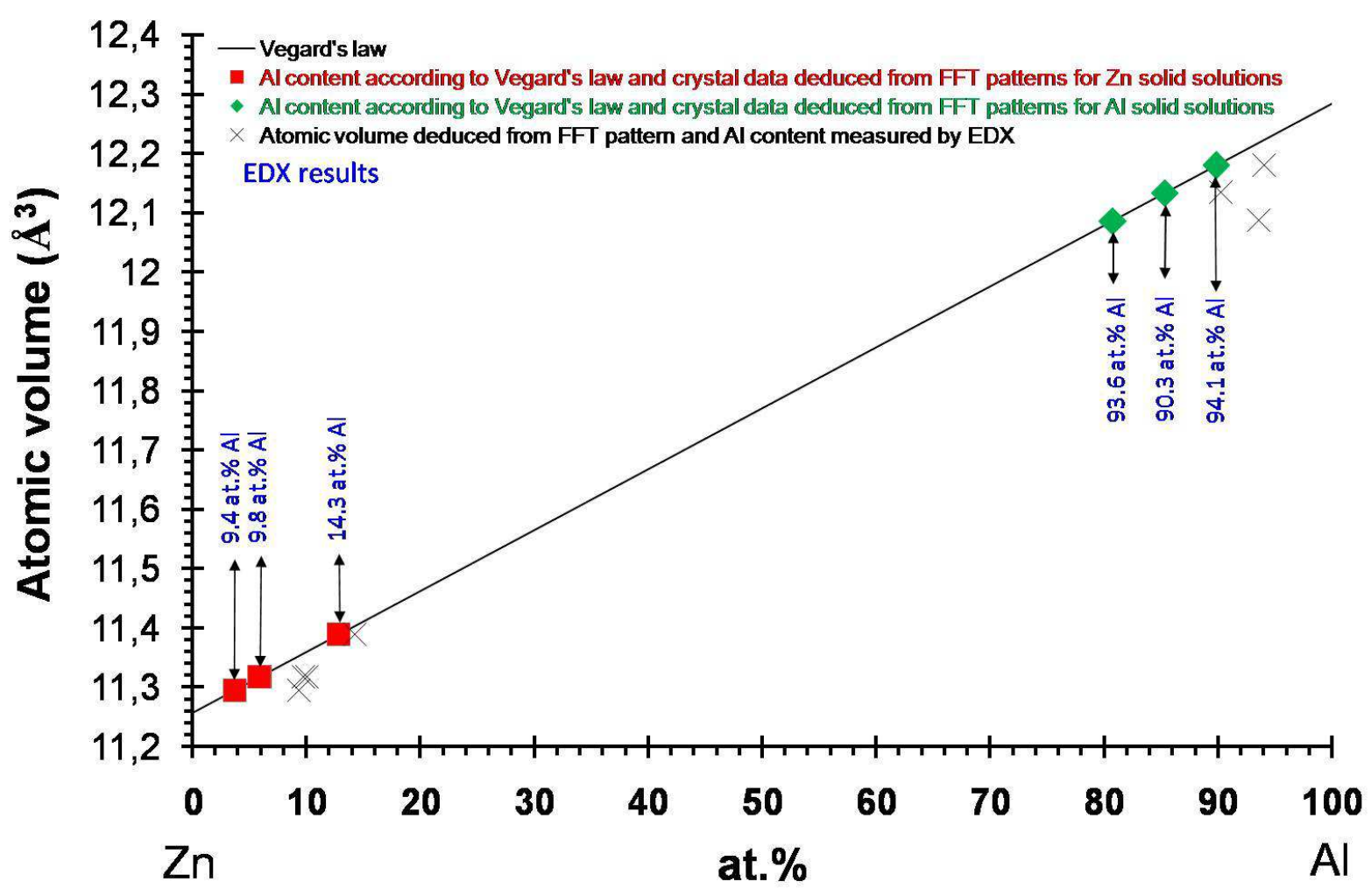

Figure 8: $\mathrm{Al}$ and $\mathrm{Zn}$ amounts in solid solution in $\mathrm{Zn}$ and $\mathrm{Al}$, respectively according to i) the Vegard's law applied to the apparent lattice parameters (red and green squares), and to ii) the EDX analyses (in blue). The coordinates of the crosses are the experimental results corresponding to the $\mathrm{Al}$ content estimated by the EDX analyses and the atomic volume deduced from the FFT patterns. Their position below the straight line corresponding to the Vegard's law suggests a negative deviation to the Vegard's law for the Al-Zn system.

In addition, for a given crystal orientation, various atom spacings have been observed in particular in the $\mathrm{Al}$ rich zones (see for instance the $\mathrm{L}$ profile in figure 9). The distances of 0.218 and $0.260 \mathrm{~nm}$ between the atoms rows are close to the $0.234(0.2025) \mathrm{nm}$ spacing between $\{111\}$ ( $\{002\})$ planes in pure Al.

The accurate observation of high resolution HAADF micrographs also puts into evidence some distortion (see for instance inside the yellow rectangle in figure 9). The distortion may result either from the presence of solute atoms in Al which leads to crystal lattice accommodation or from the proximity of strain fields due to lattice defects (dislocations, disclinations ...), internal stresses or from an undulating thin foil.

Finally, figure 10 displays the grains orientation map at the interface between the AA1050 parent metal and the $(\mathrm{Al}+\mathrm{Zn})$ mixed zone. By comparison with the $\mathrm{Al}$ (figures $10 \mathrm{~b}$ and $\mathrm{c}$ ) and $\mathrm{Zn}$ (figures $11 \mathrm{~b}$ and $\mathrm{c}$ ) base materials, the $(\mathrm{Al}+\mathrm{Zn})$ mixed zone is characterized by important changes of grain orientation in both kinds of grains. In agreement with the various Al grains orientations in the mixed zone (figure 10b), figure 10c depicts additional and less intense poles. 

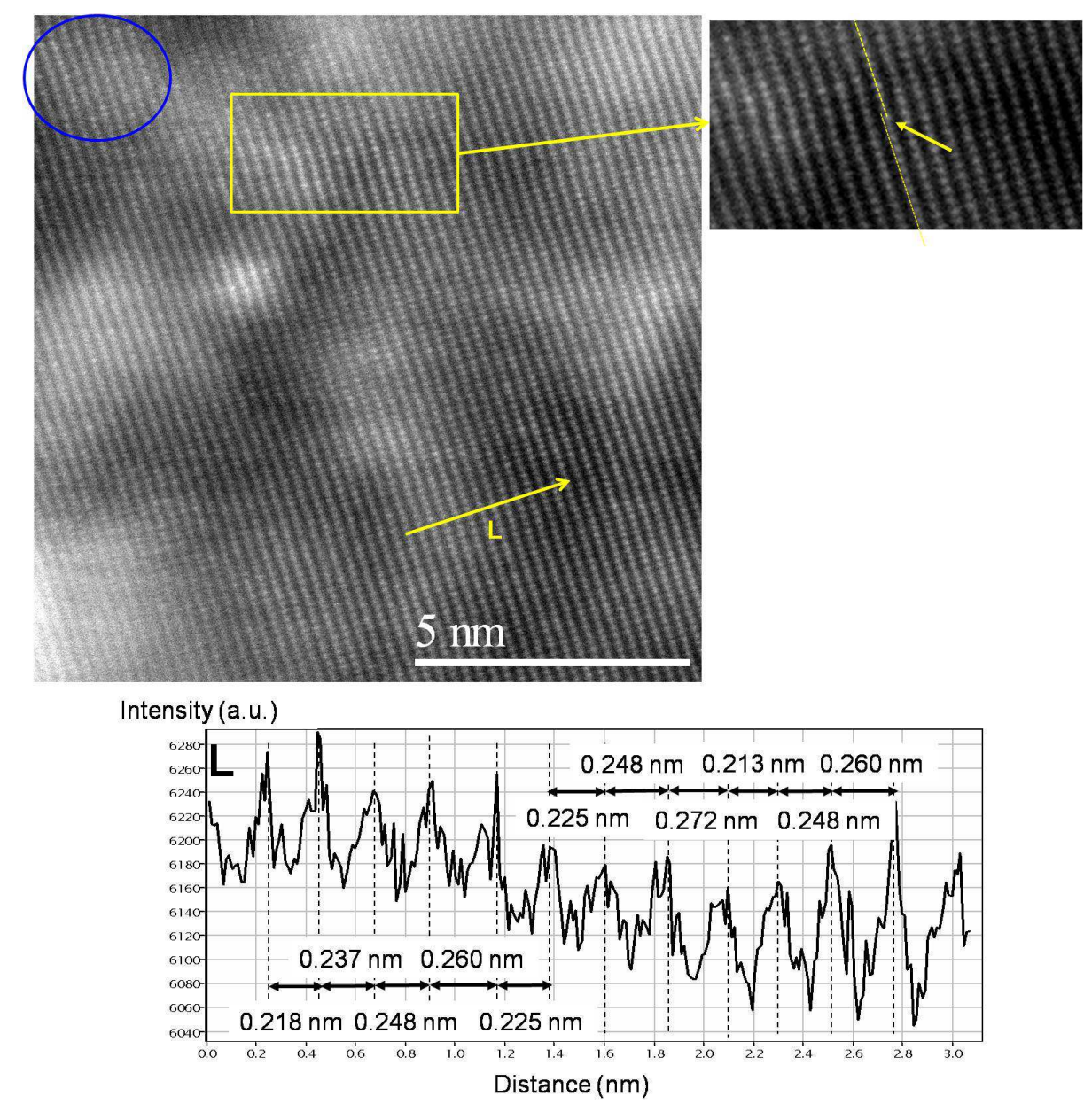

Figure 9: Al rich areas in the intermediate layer: the area surrounded with a yellow frame shows atom planes distortion along one direction.

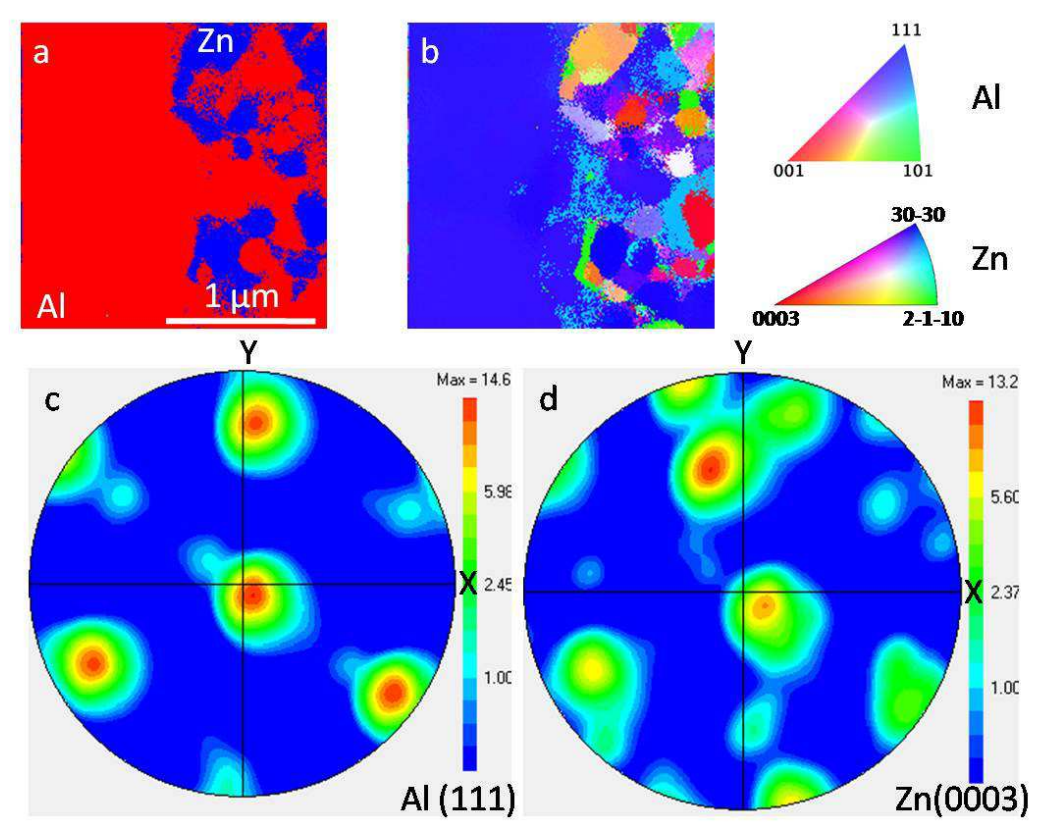

Figure 10: Orientation map of zone 3 in figure 2. Map (a) shows the distribution of $\mathrm{Al}$ and $\mathrm{Zn}$ rich phases; the $\mathrm{Al}$ and $\mathrm{Zn}$ phases are colored in red and blue, respectively. Map (b) depicts the crystal orientations of the $\mathrm{Al}$ and $\mathrm{Zn}$ grains along the normal direction, the meaning of the 
colors are indicated in the caption. (c) and (d) are the $\mathrm{Al}$ (111) and $\mathrm{Zn}$ (0003) pole figures, respectively.
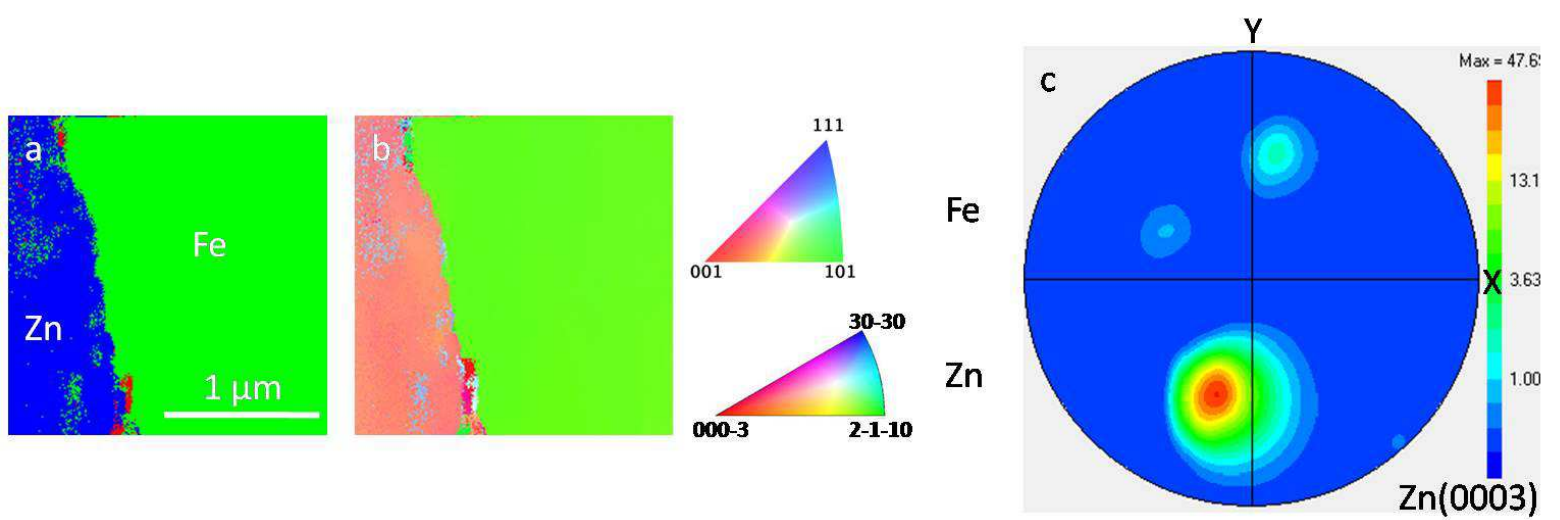

Figure 11: Orientation map of zone 4 in figure 2. The EDX map (a) shows the distribution of the Fe and $\mathrm{Zn}$ phases colored in red, green and blue, respectively. Map (b) depicts the crystal orientations of the Fe and $\mathrm{Zn}$ grains along the normal direction, the meaning of the colors are indicated in the caption. (c) is the $\mathrm{Zn}$ (0003) pole figure. Given the uncertainty about the nature of the phases contained in the inhibition layer, this layer has not been considered for the analyses.

\section{Discussion}

The analysis of the AA1050 - galvanized DP450 steel magnetic pulsed joint interface puts into evidence the successive presence of an inhibition layer, of a $3 \mu \mathrm{m}$ thick $\mathrm{Zn}$ layer and of a $8 \mu \mathrm{m}$ thick $(\mathrm{Al}+\mathrm{Zn})$ mixed layer from the steel to pure aluminum (figure 2 ).

In spite of its IMC nature, and thus brittle behavior, the inhibition layer has not been seriously fragmented during welding (see Figure 3). This impact resistance has very likely to do with both its reduced thickness and the hydrostatic state of stresses generated by its $\mathrm{Al}$ and Zn continuous surroundings [3536].

\subsection{Incomplete destruction of the primitive $\mathrm{Zn}$ layer}

The noticeable remains of the Zn layer at the joint interface can first be questioned. It is however consistent with literature results given the $11 \mu \mathrm{m}$ initial thickness of the $\mathrm{Zn}$ layer. This width is expected to exceed the usual close to $10 \mu \mathrm{m}$ thickness of the material layer ejected to form the MPW jet which is constituted of materials from both sides of the interface [3637]. The existence of a pure Zn layer without any defects of shrinkage and of a rather planar interface after welding proves that $\mathrm{Zn}$ has not melted during MPW. This result agrees with simulation data according to which a $200^{\circ} \mathrm{C}$ temperature is reached during MPW of $\mathrm{Al}$ alloy [1412]. It however contradicts some explanations [3738] and multiphysics numerical simulation data according to which temperatures, as high as $1200^{\circ} \mathrm{C}$, are reached during MPW of Al alloy [3839]. The absence of Al-Zn eutectic further pleads for a solid state process.

\section{$4.2(\mathrm{Al}+\mathrm{Zn})$ mixed layer}




\subsubsection{Origin of the $(A l+Z n)$ interfacial layer}

As aforesaid, the origin of the $8 \mu \mathrm{m}$ thick $(\mathrm{Al}+\mathrm{Zn})$ mixed layer must be considered. Two mechanisms may be proposed a priori, namely a solid state diffusion mechanism and/or a ballistic mechanism.

a) Diffusion mechanism - The diffusion coefficient of $\mathrm{Zn}$ in $\mathrm{Al}$ amounts to $2.17 \times 10^{-17}$ $\mathrm{cm}^{2} / \mathrm{s}$ and $3.63 \times 10^{-10} \mathrm{~cm}^{2} / \mathrm{s}$ at 110 and $415^{\circ} \mathrm{C}$, respectively [4] while the diffusion coefficient of $\mathrm{Al}$ in $\mathrm{Zn}$ is equal to $3.16 \times 10^{-9} \mathrm{~cm}^{2} / \mathrm{s}$ at $300^{\circ} \mathrm{C}$ [3940]. According to these data, the diffusion distances of $\mathrm{Al}$ and $\mathrm{Zn}$ would be lower than $1.78 \times 10^{-3}$ and $1.47 \times 10^{-7} \mu \mathrm{m}$ in $\mathrm{Zn}$ and $\mathrm{Al}$ for the $10 \mu \mathrm{s}$ duration of MPSW. These distances are far smaller than the $8 \mu \mathrm{m}$ thickness of the $(\mathrm{Al}+\mathrm{Zn})$ mixed layer. Solid state diffusion alone, even if promoted by the high strain and high strain rates inherent to MPSW, cannot explain the distance crossed by the $\mathrm{Al}$ and $\mathrm{Zn}$ atoms during MPW. High strains and strain rates actually generate very high densities of vacancies [78]. Thus the $(\mathrm{Al}+\mathrm{Zn})$ layer thickness cannot result from single atom diffusion during MPSW. The actual microstructure may however result from the metallographic sample preparation. The ion milling, used to prepare the thin foil, is expected to proceed at a temperature close to $400^{\circ} \mathrm{C}$ for 3 hours [4041] which should entail $\mathrm{Al}$ and $\mathrm{Zn}$ diffusion over distances of about 58.0 and $19.8 \mu \mathrm{m}$, respectively. These rough estimations exceed the $8 \mu \mathrm{m}$ thickness of the $(\mathrm{Al}+\mathrm{Zn})$ mixed $(\mathrm{Al}+\mathrm{Zn})$ layer. Complementary experiments are therefore planed in order to conclude on this eventual effect of post-welding.

b) Ballistic mechanism - In the present case, Al (low density $2.7 \mathrm{~g} / \mathrm{cm}^{3}$, high melting temperature $660^{\circ} \mathrm{C}$ ) and $\mathrm{Zn}$ (high density $7.1 \mathrm{~g} / \mathrm{cm}^{3}$, low melting temperature $419^{\circ} \mathrm{C}$ ) very likely present a similar sensitivity to ejection during MPSW like for the couple $\mathrm{Al}-\mathrm{Mg}$ [3637], $\mathrm{Al}$ - $\mathrm{Al}$ [4142] and contrary to the couples of materials $\mathrm{Al}-\mathrm{Cu}$ or $\mathrm{Al}-\mathrm{Ni}$ [4142] or $\mathrm{Al}$ - Fe $[\mathbf{1 2}, \mathbf{2 6 , 4 2 1 3 , 2 7 , 4 3 ]}$, for which the jet is essentially constituted of the lighter and lower melting point metal that is $\mathrm{Al}$. A jet comprising the $\mathrm{Al}$ and $\mathrm{Zn}$ fragments generated by the disintegration of the surfaces of the AA 1050 and $\mathrm{Zn}$ coating under the high pressure impact at high velocity is therefore formed. These fragments are of various sizes. The largest ones present a 200 to $400 \mathrm{~nm}$ size, while others are either nanometric clusters of atoms or even isolated atoms. Some oxide particles are also extracted from the surfaces and dragged in this chaotic material flow. In close contact with the surface of material not affected by the jet, the flow of a part of the resulting ballistic mixture is then very likely stopped by the surfaces asperities created by the former extracted fragments. The various fragments are propelled towards each other with a huge pressure up to $10^{5} \mathrm{MPa}[\mathbf{2 6 , 3 7 , 4 3 2 7 , 3 8 , 4 4}]$. Under such a high pressure, the largest fragments are deformed and their atoms are forced to share and exchange electrons, leading to a compact agglomerate of fragments. Thus a part of the ballistic mixture remains trapped at the joint interface and constitutes the mixed $(\mathrm{Al}+\mathrm{Zn})$ layer. This interpretation is consistent with (i) the absence of crystal orientation relationships between the $\mathrm{Al}$ and $\mathrm{Zn}$ rich grains constituting the mixed $(\mathrm{Al}+\mathrm{Zn})$ layer and (ii) the numerous miscellaneous crystal orientations of these grains (figure 10). The ballistic explanation is further consistent with literature results which showed some $\mathrm{Fe}$ fragments and discrete $\mathrm{Al}_{\mathrm{x}} \mathrm{Fe}_{\mathrm{y}}$ intermetallic particles [2627] or amorphous fragments [4445] at $\mathrm{Al} /$ steel and $\mathrm{Al} /$ metallic glass MSW joint interfaces, respectively.

In addition, the $(\mathrm{Al}+\mathrm{Zn})$ mixed area contains some $300 \mathrm{~nm}$ sized oxygen and silicon bearing particles with a spheroidal morphology (figure 4) which differs from the elongated shape of the $1 \mu \mathrm{m}$ long and $100 \mathrm{~nm}$ wide $\mathrm{Fe}$ and $\mathrm{Si}$ rich precipitates present in the primitive AA 1050 alloy (see yellow arrows in figure 2). Silicon as well as iron is an aluminum 
impurity. In the primitive aluminum alloy, and as it is the rule for raw Al 1050 alloys [4546], some $\mathrm{Al}_{X} \mathrm{Fe}_{Y} \mathrm{Si}_{\mathrm{Z}}$ precipitates are detected [3031] while silicon is not linked to iron in the mixed zone (figures 3 and 4). The presence of Si rich particles suggests that the $\mathrm{Fe}$ and $\mathrm{Si}$ bearing precipitates rich were dissolved during MPW in spite of their large dimensions. Precipitate dissolution during MPW cannot have a pure thermal origin because the lowest temperature at which $\mathrm{Al}_{x} \mathrm{Fe}_{y} \mathrm{Si}_{z}$ particles become liquid is $577^{\circ} \mathrm{C}$ via a eutectic reaction, at least at equilibrium [4647]. This temperature is significantly higher than the $200^{\circ} \mathrm{C}$ expected MPSW peak temperature [1412]. In addition, in pure thermal conditions, the respective distances covered by $\mathrm{Fe}$ and $\mathrm{Si}$ atoms in $\mathrm{Al}$ at room temperature for $10 \mu \mathrm{s}$ are shorter than $2.1 \times 10^{-4}$ and $1.5 \times 10^{-3} \mu \mathrm{m}$, these values being calculated at $520^{\circ} \mathrm{C}$ according to available data [4]. Therefore, we must conclude that the high density of vacancies generated by the intensive plastic deformation together with the disintegration during MPSW has significantly promoted the dissolution of $\mathrm{Al}_{\mathrm{X}} \mathrm{Fe}_{\mathrm{Y}} \mathrm{Si}_{\mathrm{Z}}$ precipitates, $\mathrm{Si}$ and $\mathrm{Fe}$ atomic diffusion and formation of big $\mathrm{Si}$ rich particles. The formation of Si particles has also to do with the lack of Si solubility in Al and $\mathrm{Zn}$, at least in equilibrium conditions [4]. At last, the presence of oxygen and silicon rich particles in the mixed $(\mathrm{Al}+\mathrm{Zn})$ zone is likely to result from the oxidation of the silicon particles trapped at the joint interface.

Besides, some oxygen may have penetrated into the mixed zone during the impact. According to literature, the solubility of oxygen into $\mathrm{Al}$ is $3 \times 10^{-8}$ at. $\%$ in equilibrium conditions [4748]. Literature also indicates that oxygen in oversaturation has been put into evidence by atom probe tomography at the interface of $\mathrm{Al}$ and $\mathrm{Fe}$ in $\mathrm{Al}$-steel welds elaborated at the solid state by ultrasonic additive manufacturing which proceeds at a $10^{5} \mathrm{~s}^{-1}$ shear strain rate [4849]. In such a weld, the decomposition of oxides into oxygen atoms during welding was suggested to result from the extensive plastic deformation which led to oxygen segregation to dislocations and vacancies. This interpretation may be validated in the present case of MPSW and would be consistent with the theory of ballistic mixing in metals [4950]. This approach requires huge increase in the non equilibrium defects density. As already said, numerous vacancies may have been created during MPSW since local strain rate can reach values up to $10^{7} \mathrm{~s}^{-1}$ for a few $\mu \mathrm{s}[\mathbf{2 9 , 3 8 3 0 , 3 9 ]}$. Instead of being completely ejected by the jet as usually established for MPW [3738], some oxides may have dissolved into the $(\mathrm{Al}+\mathrm{Zn})$ layer under the impact effect.

Another assumption would suggest that the adsorption of oxygen within the mixed zone may have occurred during the specimen preparation and transport. It is however less probable since, in the latter case, the preferential localization of oxygen in the mixed zone (figures 3 and 4) is not consistent with the differences of chemical affinity between $\mathrm{O}$ and $\mathrm{Al}$, $\mathrm{Fe}, \mathrm{Zn}$ and $\mathrm{Si}[4]$.

Thus the ballistic mechanism with the trapping of fragments of both the $\mathrm{Zn}$ and $\mathrm{Al}$ layers at the interface seems to be the most probable and predominant mechanism explaining the formation of the mixed $(\mathrm{Al}+\mathrm{Zn})$ area at the joint interface during MPSW. However the presence of well crystallized grains as evidenced by the FFT spot patterns (figures 5, 6 and 7) differs from other MPW results showing existence of narrow amorphous layers at $\mathrm{Al} / \mathrm{Fe}$ interfaces $[\mathbf{1 4 , 1 5 1 5 , 1 6 ]}$. It must nevertheless be noticed that amorphization as well as crystallization may arise from usual conditions of ion milling [4041]. This assumption could be checked by performing cryogenic ion milling or using oscillating (pulsed) current to avoid excessive heating [4041].

\subsubsection{Mottled areas in Al and Zn grains}


The dimensional features of the mottled contrasts in the $\mathrm{Al}$ and $\mathrm{Zn}$ rich zones (figures 5 and 6) are close to those due to spinodal decomposition in the Al- $\mathrm{Zn}$ system. This conclusion arises from the similarity of the present microstructural features with those displayed in a TEM bright field image [5051] or found by numerical simulations of spinodal decomposition [5152]. Nevertheless the present microstructure cannot arise from a spinodal separation because the 9.4 to 14.3 at\% $\mathrm{Al}$, and the 5.9 to 9.7 at\% $\mathrm{Zn}$ mean solute content in the $\mathrm{Zn}$ and Al-rich zones, respectively, are largely outside the 41 to 83.5 at\% Al limits of the incoherent miscibility gap at $277^{\circ} \mathrm{C}$ in the equilibrium $\mathrm{Al}-\mathrm{Zn}$ phase diagram [4].

The mottled contrasts are due to the presence of islands of eorrespend to oversaturated $\mathrm{Al}$ and $\mathrm{Zn}$ solid solutions (figures 5 and 6). Actually, according to the $\mathrm{Al}-\mathrm{Zn}$ equilibrium phase diagram, the solubility of $\mathrm{Al}$ into $\mathrm{Zn}$ is inexistent while that of $\mathrm{Zn}$ into $\mathrm{Al}$ is 2 at.\% at room temperature [4]. These solubility limits are clearly exceeded in the present study where the $\mathrm{Al}$ rich zones within the $\mathrm{Zn}$ based grains selid solution contains up to 22.4 at.\% $\mathrm{Al}$ and the solute rich areas in the $\mathrm{Al}$ ene based grains can reach up to 7.8 at.\% $\mathrm{Zn}$.

Like the architecture of the mixed $(\mathrm{Al}+\mathrm{Zn})$ layer, the mottled areas are very likely formed by the ballistic mixture. The presence of these solute enrichments in one grain is assumed to result from the inclusionincorporation of tiny nanometric fragments or clusters of atoms of the other material followed by their dissolutiondispersion during the impact. The incorporation of the foreign material pieces originates either from the shock between pieces or from the viscous like material flow generated by the impact. Actually, at the interface, $\mathrm{Al}$ and $\mathrm{Zn}$ very likely behave as high velocity fluids because of the high strain rates and the great pressures up to $10^{5} \mathrm{MPa}[\mathbf{2 6 , 3 7 , 4 3 2 7 , 3 8 , 4 4 ]}$. The viscous state would be induced by the great atomic disorder due to a high density of vacancies generated by the high strain rate reaching values up to $10^{7} \mathrm{~s}^{-1}$ for a few $\mu \mathrm{s}[\mathbf{2 9 , 3 8 3 0 , 3 9 ]}$. It is worth noting that the very short duration of welding and-the temperature and duration of ion milling were not sufficient to reach equilibrium, which should imply repulsion between $\mathrm{Al}$ and $\mathrm{Zn}$ rather than homogenization of solid solutions.for the homogenization of the solute content in the grains. The anomalous $\mathrm{Si}$ contents of the grains in the $(\mathrm{Al}+\mathrm{Zn})$ layer probably have a similar ballistic origin. According to the EDX results in figures 5 and 6 , and in contradiction with the equilibrium solubility limits the $\mathrm{Zn}$ rich grains are more oversaturated in $\mathrm{Si}$ than the $\mathrm{Al}$ rich grains. Besides it is worth noting that the $\mathrm{Si}$ content of the $\mathrm{Zn}$ rich grains exceeds its nominal content in the AA1050 alloy (figure 6).

\section{Conclusions}

The characterization at the atomic scale of the singular biphased layer contained in the Al -galvanized steel MPW joint supplies clues about its ballistic origin. This conclusion originates from the following observations:

(i) The layer displays a random distribution of $\mathrm{Al}$ and $\mathrm{Zn}$ rich grains with various crystal orientations and heterogeneous chemical compositions.

(ii) The grains are Some oversaturated $\mathrm{Al}$ and $\mathrm{Zn}$ based solid solutions with local solute enrichments are locally observed in the grains.

Besides, the important layer thickness and the dissolution of very large particles must be noted since they cannot result from single atomic diffusion even aided by the very high strain rates inherent to MPW. The dissolution of the large particles rather arises from their desintegration.

The absence of both solidification defects and Al-Zn eutectic as well as the planar interface morphology prove that the bonding interface has formed without melting. 


\section{Aknowledgments}

The authors are very grateful to Pr. G. Racineux, Ecole Centrale de Nantes - France, to have provided the joints and to D. Troadec, IEMN, France for having performed thin foil cutting by FIB. The TEM facility in Lille (France) is supported by the Conseil Régional du Nord-Pas de Calais, and the European Regional Development Fund (ERDF).

\section{Data availability}

All the data in this manuscript are available upon request to the corresponding author.

\section{References}

[1] F. Möller, C. Thomy, Handbook of laser welding technologies, Chapter 9: Laser welding and brazing of dissimilar materials, Woodhead publishing (2013) 255-279.

[2] L.H. Shah, M. Ishak, Review of research progress on aluminium-steel dissimilar welding, Mater. Manuf. Processes. 29 (2014) 928-933.

[3] G. Sierra, Etude métallurgique et mécanique de l'assemblage hétérogène accier/aluminium par les procédés laser et TIG, Université Montpellier 2, PhD (2006).

[4] E.A. Brandes, G.B. Brook, Smithells Metal Reference Book, seventh edition, Oxford (1992).

[5] M. Kutsuna, H. Ozaki, S. Nakagawa, K. Miyamoto, Laser roll welding of dissimilar metal joint of zinc coated steel and aluminum alloy, Proceedings of the $4^{\text {th }}$ International congress on laser advanced materials processing, Kyoto (Japan), 2006

[56] T. Tanaka, T. Morishige, T. Hirata, Comprehensive analysis of joint strength for dissimilar friction stir welds of mild steel to aluminum alloys, Scripta Mater. 61 (2009) 756759.

[67] K. Masaki, Y.S. Sato, M. Maeda, H. Kokawa, Experimental simulation of recrystallized microstructure in friciton stir welded $\mathrm{Al}$ alloy using a plain-strain compression test, Scripta Mater. 58 (2008) 355-360.

[78] M. Militzer, W.P. Sun, J.J. Jonas, Modelling the effect of deformation-induced vacancies on segregation and precipitation, Acta Metall. Mater. 42 (1994) 133-141.

[89] S.H. Carpenter, Chapter 53: S.H. Carpenter: Explosion welding: a review in Shock waves and high strain rate phenomena in metals. Concepts and applications ed. MA Meyers, LE Murr, Plenum press, New York (1981) 941-959.

[910] M.P. Bondar, V.M. Ogolikhin, Plastic deformation in bonding zone under explosive welding and its role in bonding formation, J. Phys. 46(5) (1985) 379-384.

[1011] A. Kapil, A. Sharma, Magnetic pulse welding: an efficient and environmentally friendly multi-material joining technique, J. Clean Prod. 100 (2015) 35-38. 
[1112] R.M. Miranda, B. Tomas, T.G. Santos, N. Fernandes, Magnetic pulse welding on the cutting edge of industrial applications, Soldag Insp Sao Paulo 19(01) (2014) 69-81.

[1213] T. Aizawa, M. Kashani, K. Okagawa, Application of magnetic pulse welding for aluminum alloys and SPCC steel sheet joints, Weld. J. 86 (2007) 119-s - 124-s.

[1314] H.P. Yu, Z.D. Xu, Z. Fan, Z. Zhao, C. Li, Mechanical property and microstructures of aluminium alloy-steel tubes joint by magnetic pulse welding., Mater. Sci. Eng. A 561 (2013) 259-265.

[1415] J. Li, Q. Yu, Z. Zhang, W. Xu, X. Sun, Formation mechanism for the nanoscale amorphous interface in pulse-welded Al/Fe bimetallic systems, Appl. Phys. Lett. 108 (2016) 201606.

[1516] Z. Fan, H. Yu, C. Li, Interface and grain-boundary amorphization in the Al-Fe bimetallic system during pulsed-magnetic-driven impact, Scripta Mater. 110 (2016) 14-18.

[1617] H.P. Yu, Z.D. Xu, H.W. Jiang, Z.X. Zhao, C.F. Li, Magnetic pulse joining of aluminum alloy - carbon steel tubes, Trans. Nonferrous Met. Soc. China. 22 (2012) s548s552.

[1718] H. Yu, Z. Fan, C. Li, Magnetic pulse cladding of aluminum alloy on mild steel tube, J. Mater. Proc. Technol. 214 (2014) 141-150.

[1819] J.Y. Shim, I.S. Kim, M.J. Kang, I.J. Kim, K.J. Lee, B.Y. Kang, Joining of aluminium to steel pipe by magnetic pulse welding, Mater. Trans. 52(5) (2011) 999-1002.

[1920] Z. Fan, H. Yu, C. Li, Plastic deformation behavior of bi-metal tubes during magnetic pulse cladding: FE analysis and experiments, J. Mater. Process. Technol. 229 (2016) 230-243.

[2021] A. Ben-Artzy, A. Stern, N. Frage, V. Shribman, O. Sadot, Wave formation mechanism in magnetic pulse welding, Intern. J. Impact. Eng. 37 (2010) 397-404.

[2122] A. Lorenz, J. Lueg-Althoff, G. Göbel, C. Weddeling, E. Beyer, A.E. Tekkaya, Influence of axial workpiece positioning during magnetic pulse welding of aluminium-steel joints, 6th International Conference on High Speed Forming (2014) 189-198.

[2223] I. Oliveira, P. Teixeira, A. Reis, Magnetic pulse welding of dissimilar metals: influence of process parameters. 6th International Conference on High Speed Forming (2014) 117-126.

[2324] J. Cui, G. Sun, J. Xu, Z. Xu, X. Huang, G. Li, A study on the critical wall thickness of the inner tube for magnetic pulse welding of tubular Al-Fe parts, J. Mater. Process. Technol. 227 (2016) 138-146.

[2425] A.P. Manogaran, P. Manoharan, D. Priem, S. Marya, G. Racineux, Magnetic pulse spot welding of bimetals, J. Mater. Process. Technol. 214 (2014) 1236-1244. 
[2526] A.P. Manogaran, P. Manoharan, D. Priem, S. Marya, G. Racineux, Magnetic Pulse Spot Welding: Application to Al/Fe Joining. 6th International Conference on High Speed Forming (2014) 89-96.

[2627] K.J. Lee, S. Kumai, T. Arai, T. Aizawa, Interfacial microstructure and strength of steel/aluminium alloy lap joint fabricated by magnetic pressure seam welding, Mater. Sci. Eng. A 471 (2007) 95-101.

[2728] M. Geyer, A. Rebensdorf, S. Böhm, Influence of the boundary layer in magnetic pulse sheet welds of aluminium to steel, 6th International Conference on High Speed Forming (2014) 51-60.

[2829] S.D. Kore, P.P. Date, S.V. Kulkarni, Electromagnetic impact welding of aluminum to stainless steel sheets, J. Mater. Process. Technol. 208 (2008) 486-493.

[2930] Y. Zhang, S.S. Babu, C. Prothe, M. Blakely, J. Kwasegroch, M. LaHa, G.S. Daehn, Application of high velocity impact welding at varied different length scales, J. Mater. Process. Technol. 211 (2011) 944-952.

[3031] M.-N. Avettand-Fènoël, C. Khalil, R. Taillard, G. Racineux, Effect of steel galvanization on the microstructure and mechanical performances of planar magnetic pulse welds of aluminum and steel, Met. Mat. Trans. A 49 (2018) 2721-2738.

[3132] A.R. Marder, Metallurgy of zinc coated, Prog. Mater. Sci. 45(3) (2000) 191-271.

[3233] P. Hartel, H. Rose, C. Dignes, Conditions and reasons for incoherent imaging in STEM, Ultramicroscopy 63 (1996) 93-114.

[3334] R.W. Cahn, P. Haasen, Physical Metallurgy, Part I, Elsevier Science Publishers, Amsterdam (1983).

[3435] H.E. Von Steinwehr, Causes of deviation from Vegard's law, Zeitschrift für Kristallographie, Kristallgeometrie, Kristallphysik, Kristallchemie 125(1-6) (1967) 360-376.

[3536] G.E. Dieter, Fundamentals of metalworking in Mechanical Metallurgy, $2^{\text {nd }}$ Edition, McGraw-Hill Kogakusha Ltd., Tokyo (1976) 572-576.

[3637] A. Stern, O. Becher, M. Nahmany, D. Ashkenazi, V. Shribman, Jet composition in magnetic pulse welding: Al-Al and al-Mg couples, Weld. J. (2015) 257-s-264-s.

[3738] V. Psyk, D. Risch, B.L. Kinsey, A.E. Tekkaya, M. Kleiner, Electromagnetic forming a review, J. Mater. Proc. Technol. 211 (2011) 787-829.

[3839] T. Sapanathan, R.N. Raoelison, N. Buiron, M. Rachik, In situ metallic porous structure formation due to ultra high heating and cooling rates during an electromagnetic pulse welding, Scripta Mat. 128 (2017) 10-13.

[3940] S. Cui, Y. Du, L. Zhang, Y. Liu, H. Xu, Assessment of atomic mobilities in fcc Al-Zn and Ni-Zn alloys, Calphad 34 (2010) 446-451. 
[4041] B. Viguier, A. Mortensen, Heating of TEM specimens during ion milling, Ultramicroscopy 87 (2001) 123-133.

[4142] S. Kakizaski, M. Watanabe, S. Kumai, Simulation and experimental analysis of metal jet emission and weld interface morphology in impact welding, J Japan Institute Light Metals 61(7) (2011) 328-333.

[4243] M. Watanabe, S. Kumai, K. Okagawa, T. Aizawa, In-situ observation of magnetic pulse welding process for similar and dissimilar lap joints using a high speed video camera, Aluminum alloys 2 (2008) 1992-1997.

[4344] V. Shribman, Magnetic pulse welding for dissimilar and similar materials. Proceedings $3^{\text {rd }}$ International Conference on High Speed Forming, Dortmund, Germany (2008) 13-22.

[4445] M. Watanabe, S. Kumai, G. Hagimoto, Q. Zhang, K. Nakayama, Interfacial microstructure of aluminum / metallic glass lap joints fabricated by magnetic pulse welding, Mat. Trans. 50(6) (2009) 1279-1285.

[4546] A. Anghelus, M.-N. Avettand-Fènoël, C. Cordier, R. Taillard, Microstructural evolution of aluminium/Al-Ni-Sm glass forming alloy laminates obtained by controlled accumulative roll bonding, J. All. Cpnds. 631 (2015) 209-218.

[4647] G.V. Raynor, V.G. Rivlin, Phase equilibria in iron ternary alloys, a critical assessment of the experimental literature, 'Al-Fe-Si', The Institute of Metals, London (1988).

[4748] H. Wriedt, The Al-O (aluminum-oxygen) system, J. Phase Equilibria 6(6) (1985) 548553.

[4849] N. Sridharan, D. Isheim, D.N. Seidman, S.S. Babu, Colossal super saturation of oxygen at the iron-aluminum interfaces fabricated using solid state welding, Scripta Mater 130 (2017) 196-199.

[4950] A.C. Lund, C.A. Schuh, Driven alloys in the athermal limit, Phys. Rev. Lett. 91(23) (2003) 235505

[5051] T. Miyazaki, T. Koyama, T. Kozakai, Computer simulations of the phase transformation in real alloy systems based on the phase field method, Mater. Sci. Eng. A 312(1-2) (2011) 38-49.

[5152] V.M. Lopez-Hirata, E.O. Avila-Davila, M.L. Saucedo-Munoz, J.D. Villegas-Cardenas, O. Soriano-Vargas, Analysis of spinodal decomposition in Al- $\mathrm{Zn}$ and $\mathrm{Al}-\mathrm{Zn}-\mathrm{Cu}$ alloys using the non-linear Cahn-Hilliard equation, Mater. Res. 20(3) (2017) 639-645. 